\title{
Executive Functions in Alzheimer's Disease: A Systematic Review
}

\author{
Priscilla Chantal Duarte Silva ${ }^{\mathrm{a}, *}$, Larissa Leite Vieira de Oliveira ${ }^{\mathrm{b}}$, Ricardo Luiz Perez Teixeira ${ }^{\mathrm{a}}$, \\ Max Leandro de Araújo Brito ${ }^{c}$ and Anna Rita Tomich Magalhães Filippe ${ }^{a}$ \\ ${ }^{a}$ Universidade Federal de Itajubá, Itabira, State of Minas Gerais, Brazil \\ ${ }^{\mathrm{b}}$ Escola de Medicina da Universidade Federal de Ouro Preto, State of Minas Gerais, Brazil \\ ${ }^{\mathrm{c}}$ Faculdade de Engenharia, Letras e Ciências Sociais do Seridó da Universidade Federal do Rio Grande do \\ Norte, State of Rio Grande do Norte, Brazil
}

Received 11 November 2021

Accepted 15 January 2022

Pre-press 15 February 2022

Published 24 February 2022

\begin{abstract}
. and connection with memory. how they are compromised in this pathology. the objective, an integrative literature review was adopted. of dementia. and attention are the most evident in this type of dementia.

\section{INTRODUCTION}

The term cognition has a Latin origin (Latin $\operatorname{cog}$ nitio, -onis, the action of knowing), related to the ability to understand the world. It is a mental faculty of obtaining knowledge, hence the correlation

\footnotetext{
${ }^{*}$ Correspondence to: Prof. Priscilla Chantal, Universidade Federal de Itajubá Campus Itabira, Rua Irmã Ivone Drumond, 200, sala 2432, Distrito Industrial II, Itabira, State of Minas Gerais, 35903087, Brazil. Tel.: +55 31 38390848/ +55 31 9872620764; E-mail:
} priscillachantal@unifei.edu.br.
\end{abstract}

Background: In Alzheimer's disease, in addition to memory, attention has been given to cognitive testing due to its interface

Objective: The aim of this study is to take a global view of executive functions and place the concept within the theoretical framework of Alzheimer's disease dementia, verifying their role in the cognitive functioning of the human mind, as well as

Methods: An initial search was carried out in databases such as PubMed, ScienceDirect, and Web of Science. The guiding question presented at the end of the introduction was elaborated from the PICO/PIO/PEO strategy. The selected articles, therefore, answered the guiding question, were made available in full, and published in the period from 2000 to 2020. Studies without specific methodology and which correlated with other diseases or other types of dementia were excluded. To meet

Results: The results indicate that, although the tests to verify the performance of cognitive functions have their limitations, they bring some evidence that they have been compromised, especially when analyzed periodically during the development

Conclusion: It is concluded that there is an interference of executive functions in function of Alzheimer's and that memory

Keywords: Alzheimer's disease, cognition, executive functions, integrative literature review, PICO strategy

with knowing. The term is not new and dates to the Middle Ages [1].

The terms of the Cognition family initially appear in the literature only in the 17 th and 19 th centuries [1]. What is not known for certain is how these terms first appear in the literature. In another perspective, cognition is understood as a form of mental representation based on perception [2]. However, cognitive processes do not end with representation. They are also geared toward the transformation, storage, retrieval, and use of the input data that comes to mind. In other 
words, human cognition refers to the ability to process information received from different external sources, and this consists of different processes such as learning, attention, memory, language, reasoning and interpretation, and decision making, which are part of human development. Cognitive Psychology includes thinking, memory, perception, problem solving, intelligence, language, and creativity [3].

Cognition is understood, within Psychology, in terms of information processing and the functional level that tries to explain behavior through elements of the environment, which can influence it [4]. In an operational view, cognition refers, at its root, to activities through which sensory input is referred to as mental operations. If you think about the representational character, so that the external representations signify the output elements, it is also possible to think about cognition being also affected by cultural issues or phenomena [5]. This implies a cognitive view of how people represent information and how these representations are processed. The human cognition was like computer programming [6]. Cognitive performance is usually defined in terms of functioning domains [7].

This ability to perform tasks or the set of cognitive skills is what they call executive function (EF). Usually, they are considered as the set of functions capable of allowing a human being to perform actions. The term is considered as the ability to formulate objectives, plan, and execute [8]. So, any damage or loss of these functions compromises the individual's capacity for independence and to have a productive life.

In the history of Neuropsychology, EF received several definitions [9]. They are also called executive control or cognitive control [10]. There are other synonyms for the term such as executive functioning, executive skill, among others [11]. Often, the term "cognitive functions" is also used in place of EFs. However, the cognitive functions concern how much knowledge, skill, and intellectual equipment a person has [8].

The term EF is the most used because it refers to the ability to perform tasks. EFs have to do with how much the person can do. In an assessment, the responsible professional investigates which skills are preserved and which are deteriorated.

In neuropsychological assessments, conditions are assessed, that is, whether the individual still maintains cognitive abilities preserved or if there is any deterioration. The evaluation consists of an analysis of: 1) pre-morbidity; 2) general intellectual level;
3) memory; 4) language; 5) calculation; 6) problem solving; 7) alertness and attention; and 8) visual and spatial perception. The fundamental areas of cognitive functions are intelligence, memory, and language [12].

By the 1940s, life expectancy in Brazil was no more than 46 years of age. According to information released by the Brazilian Institute of Geography and Statistics (2020), in 2019, the estimate reaches 76 years of age, with equally superior quality when compared to the $40 \mathrm{~s}$. As the population ages, there is a gradual increase in dementias. "Dementia" is a set of diseases that develop from the death of brain nerve cells (neurons) or the loss of their functions [13].

"Dementia" process leads to a series of changes in memory, thought formulation, and other basic behaviors of the individual. Also, Alzheimer's disease (AD) is the most common type of dementia, whose onset occurs through an unconscious preclinical stage with mild cognitive impairment (MCI), progressing to a severe state with progressive and irreversible injuries.

The diagnosis of dementia is made considering the deficit of memory and other cognitive function associated with a social and occupational commitment [14]. The diagnosis requires assessment of cognitive abilities. AD is defined as a type of dementia of degenerative cause, predominantly cortical, from a neuro functional anatomy point of view, whose evolution brings changes in multiple cognitive functions.

The symptoms of AD can vary between affected individuals [15]. The most common complaints, however, are related to memory decline, language disorders, loss of the ability to solve everyday activities, and deficiency of other cognitive skills.

At the beginning of the onset of $\mathrm{AD}$, it is normal to complain about forgetfulness related to recent events. This is because the part of the brain primarily affected is responsible for the formation of new memories [13]. Then, as the disease progresses, other regions are affected, which explains the extent of the symptoms.

The definitive diagnosis shows the deposition of amyloid- $\beta$ (A $\beta$ ) protein-abnormal and insoluble, which cannot be removed by the cells, neuritic plaques - accumulation of dead cells around the amyloid protein, and neurofibrillary plaits in the nervous tissue [16]. A $\beta$ and tau biomarkers are primary indicators of $\mathrm{AD}$ [17].

At the clinical level, mental state assessment tests are applied, which consist of simple questions and tasks that help in the diagnosis of dementia. The very commonly used test in some countries is the 
Mini-Mental State Examination (MMSE), whose assessment can be performed in a simplified and quick way in the offices [18].

Following the clinical criteria for diagnosing AD, the diagnosis comprises a series of observations such as progressive deterioration of specific cognitive functions, such as language (aphasia), motor skills (apraxia), and perception (agnosia); impaired activities of daily living and altered patterns of behavior; family history of similar disorders, particularly if confirmed neuropathologically; in addition to laboratory results [19].

Changes in the brain occur in the presence of neuropathologies and cognitive decline [20, 21]. These neuropathological changes are common in the aging process even among adults with normal cognition [22]. However, it is in AD that such declines are more pronounced, affecting cognition [23] and the decline in executive functioning [24].

The decline in memory in aging is the result of a series of factors that influence EFs and the memory system. Memory problems are more visible in tasks that require a higher level of attention and control processes, which suggests a correlation between the system of functions. It is known that, in $\mathrm{AD}$, some cognitive domains are more affected than others. For example, long-term memory and working memory (WM) are the most affected, while vocabulary meaning and priming effect remain intact [25, 26].

Adults with MCI have problems with WM and EF [27]. In the case of $\mathrm{AD}$, these problems are more pronounced compared to those normally associated with aging. MCI can lead to AD in many cases. There are indications that there may be a reversal, towards a recovery of cognitive function at the beginning of the impairments [27, 28]. Other studies, however, point out that AD is an irreversible syndrome, characterized by a slow and progressive cognitive decline that interferes with the essential functions of daily life [29].

EF correlates with memory because, for it to function well, there is a processing that involves it as the strategic elaboration during memorization and the guiding search in data recovery [24]. These mental faculties correspond to human cognition.

EF refers to a set of processes that include awareness, processing and evaluation, planning, task execution and self-monitoring, and regulation [30]. Individuals with $\mathrm{AD}$ have a deterioration in EFs, affecting all these processes [27].

The key question is to understand how physiological changes cause changes in the cognitive domains and how they interact with each other. Therefore, the objective of this study is to investigate the level of impairment of EFs by $\mathrm{AD}$, which is the most compromised function, and how the MMSE assesses cognitive competences.

\section{Understanding EFs in the literature}

The term EF comprise a set of several cognitive processes [31]. Through EFs, it is possible to observe the subject's intellectual behavior [8], as well as to analyze intelligence, the use of verbal components, sensory modalities, perception, response, memory, concept formation, and reasoning activities. It is in this sense, therefore, that EFs are linked to mental faculties. Although they are typically distinct operations, EFs are not isolated functions, but that they result from an interaction between various parts of the brain [9]. EFs are as a multidimensional system [32].

EFs refer to a cognitive domain that holds several competencies [33]. EFs include a variety of skills that range from objective to targeted behavior, strategic selection, monitoring information, and planning the sequencing of actions [34]. EFs allow the individual to work with ideas, think before acting, adapt to new situations, avoid temptations, and stay focused [35].

EFs have not only received attention in the literature on $\mathrm{AD}$ but have also been part of the diagnosis of the disease [31]. The commitment of EFs to AD has been widely discussed $[27,31,35]$. In the type of $\mathrm{AD}$ dementia, progressive cognitive decline is observed, including loss of memory, language, or EF and subsequent decline in social function in activities of daily living.

There is a certain dysfunction in EFs relatively at the beginning of $\mathrm{AD}$, especially concerning to executive attention [36]. A pattern of neuropsychological test series includes many analyses of the EFs, such as WAIS-R Digit Symbol Substitution, Digit Span Backwards, Trails A and B, and clock-drawing, all of which involve more than one cognitive domain, but all related to attentional control.

The executive care network is the most prominent factor in $\mathrm{AD}$, which states that attention seems to be significantly affected [36]. So, there is importance of attention and its correlation with memory in the act of reading and the cognitive aspects of reading in patients with AD [25].

However, it is worth remembering that although people close to $\mathrm{AD}$ patients report that in addition to recent memory problems, the focus of atten- 
tion decreases with the disease, first of all, episodic memory is affected in $\mathrm{AD}$, with atrophy associated with limbic regions and subsequently other functions. In addition to episodic memory, problems of semantic memory and WM can also be included [37].

As attention is complex and indispensable for memorization, it can be considered a reasonable explanation for the correlation between memory and attention [35]. More recent studies have drawn attention to the correlation between the two functions. AD is a neurodegenerative disease that has a progressive cognitive deficit and believes that several rarer variants of $\mathrm{AD}$ present apparent memory preservation [38]. In fact, studies on AD care require more guidance. So, the memory is the most recognized and evident characteristic in $\mathrm{AD}$, but describes those other cognitive deficits such as aphasia, cognitive dysfunction, apathy, or personality change have also been frequently discussed in the literature.

It is worth remembering that it is necessary to consider attention deficiencies as a vital component to trace the cognitive profile in $\mathrm{AD}$. The attention can be a precursor to mild amnestic cognitive impairment in people at risk for AD [31]. Memory problems may appear later. The increased interest in EF studies is because many cognitive tests useful in predicting which elderly people will develop dementia include executive control requirements. For them, episodic memory is the cognitive domain most affected in AD.

In the case of EFs, the greatest perception is for deficits in problem-solving, planning, and organizing behavior and ideas, abstraction, judgment, cognitive flexibility, decision making, WM, and self-monitoring. However, in neuropsychological assessments, what is usually evaluated is attention, concentration, stimulus selection, abstraction capacity, control, and WM. In general, neuropsychological assessments include observations, interviews, and psychological tests.

The attention and executive deficit are frequent and disabling symptoms in MCI, assessed with neuropsychological tests ranging from simple processing speed tasks to complex problem-solving tasks [39]. As they are symptoms, they may be an indication for a future memory deficit.

EFs are linked to a series of activities. There are three main EFs: inhibition, inhibitory control, including self-control and selective attention and collective inhibition, WM, and cognitive flexibility [10]. Inhibitory control refers to the ability to control attention, behavior, thoughts, and/or emotions. Without it, the subject is driven to impulses, having no control over his actions.

The inhibitory control of attention (control of interference at the level of perception) allows the selection process, that is, it refers to the ability to choose and suppress attention to other stimuli. With this control, the subject can pay attention to something according to his intention. It is a control of attention or attentional inhibition [10]. With this ability, it is possible to resist unwanted thoughts or memories and resist interference. The self-control is the aspect of inhibitory control that involves mastery over behavior and emotions and is directly linked to WM. In this regard, self-control is about resisting situations and not acting on impulse, which can be related to discipline, maintaining focus, as well as knowing how to wait.

The self-control is like what cancels or inhibits the automatic, habitual or innate, behaviors, impulses, emotions, or desires [40]. They also emphasize that the ability to exercise self-control over one's thoughts and behaviors is crucial for several situations, such as motor control (staying in a position, when necessary), control over immediate temptation at the expense of something later, emotional control in the face of contexts that they demand not to act on impulse. Concerning neural bases, the right ventrolateral prefrontal cortex (rVLPFC) is a neural region commonly recruited in many different forms of self-control.

Another important function is WM, which involves keeping the information in mind and working with it mentally. In other words, it consists of keeping the information in mind and manipulating it. So, mathematical operations, reordering and reorganizing items in a list, instructions in action plans, relating information are specific to WM [10]. Without it, the reasoning would not be possible.

Asking people to rearrange the items they heard is an excellent exercise for measuring WM [10]. WM is a limited capacity system that allows you to temporarily process, store and manipulate information in conscious awareness, such as memorizing a phone number while preparing to dial it, recording a spoken phrase while processing the meaning. Patients with deficits in WM may report distraction and concentration problems [41].

WM decreases with aging, related to the decline in cognitive processing [42, 43]. Researchers often use complex tasks to assess WM, such as counting interval or reading interval [10]. However, he contests that these tasks require more subcomponents of EFs than of WM alone. In this regard, the EFs evaluation 
process is questioned. After all, there is no consensus on which components of EFs a task requires.

Cognitive flexibility is the third core of EFs. It consists of the ability to change perspective, either spatially, when the individual changes the perspective of an object, for example, or interpersonal, when evaluating a point of view from another perspective. To change the perspectives, it is necessary to inhibit or disable the previous one and load a distinct perspective into the WM [10]. Thus, cognitive flexibility is related to inhibitory control. Tests that involve verbal and semantic fluency work with this flexibility, when the subject must mentally elaborate a list of items with the same letter, for example, or how many uses the same word can contain, or alternating names $[10$, 44].

Patients with $\mathrm{AD}$ frequently showed deficits in a variety of standard tests of EF and attention [37]. Besides, the patients with $\mathrm{AD}$ also tend to have deficits in tests of immediate conversation recall [45]. It is necessary to include tests of WM, attention, and EFs in the same study so that it is possible to draw clearer relationships between assessments of dementias.

The cognitive decline, related to aging, also affects aspects of language comprehension and production, and affirm that simpler linguistic skills such as object naming involve extensive brain networks [46]. Consequently, they consist of skills that can be easily interrupted, which makes linguistic competence an indicator of mental dysfunction. The diagnosis of $\mathrm{AD}$ is made with observations and examinations.

The language disorders are common symptoms at the beginning of $\mathrm{AD}$, especially about the difficulty of finding words [38]. In general, EFs tests assess cognition globally in terms of attention, constructive visual skills, language, and memory. However, some studies draw attention to the need for a deeper and more comprehensive analysis [47]. The level of education, and socioeconomic showed differences in test results $[34,47]$. This shows that EFs should be better analyzed considering correlational factors.

Clinical examinations include the MMSE for cognitive screening; Blessed Dementia Scale for clinical symptoms and social function; the Hamilton Depression Scale for the severity of depression; the Current State Examination for anxiety, depression, delusions, and hallucinations; and the Hachinski Scale to estimate the probability of multi-infarct dementia [48]. A complete psychiatric evaluation is necessary to exclude the various psychiatric disorders. In addition, a thorough examination of the sensory and motor systems (including cranial nerves, tone, reflexes, coordination, gait, and proprioception) is necessary to exclude other neurological disorders. Cognitive screening tests are important to assist in the diagnosis of $\mathrm{AD}$, as well as to evaluate the evolution [49].

The tests commonly used to detect dementias are Montreal Cognitive Assessment [50]; MMSE or Mini-Cog; Interview-based assessments; Informant's Questionnaire on Cognitive Decline in the Elderly or Quick Dementia Rating System. Regarding these tests, they usually capture memory deficiency, however, other important domains, such as attention and $\mathrm{EF}$, may not be well-identified. This is unfortunate because changes in the resolution of executive problems and decision-making can be one of the first signs of MCI and AD.

\section{The neurobiological bases of $A D$ and the role of the MMSE}

$\mathrm{AD}$ is characterized as a disease of individuals of advanced age. Normally, the incidence increases from the age of 65 , and the appearance of symptoms in younger groups is unusual [51]. It is a neurodegenerative disease whose causes are not yet well defined [52]. Neurological impairment starts from cerebral atrophy in the medial temporal lobes, then disseminated to the temporal, medial, and lateral parietal lobes, in addition to the lateral frontal cortex [53].

Several aspects can be observed in the pathogenesis of AD. To understand them, it is necessary to know that the normal aging process progresses with the accumulation of neuritic plaques, in small amounts, in the nervous tissue. These are also called senile plaques or neurofibrillary tangles [54]. However, patients with AD express an abnormal accumulation of this substance, the cause of which is not yet fully explained. In view of this, some theories have been drawn up over the years to elucidate the origin of nervous tissue impairment [55].

The amyloid cascade hypothesis that defends the idea that $\mathrm{AD}$ is a proteinopathy, caused by increased production and abnormal deposition of $\mathrm{A} \beta$ protein [56]. Thus, if such production is prevented or reversed, it becomes possible to interrupt the progress of the disease, which justifies the adoption of immunotherapy against $A \beta$ [57]. Another wellstudied hypothesis is genetics. In cases of early AD, the responsible genes were identified present on chromosomes 14, 1, and 21.

On chromosome 21, for example, an excess amount of the amyloid precursor protein $(A P P)$ gene 
was detected, which results in excess amyloid production in the brain [58]. In addition, there is evidence of mutations in APP genes between groups with familial AD. This investigation in members of families with familial AD enabled the discovery of other genes involved in the etiopathogenesis, presenilins [59]. An individual who inherits any of the mutations in the genes for presenilins 1 or 2, will certainly develop AD before the age of 65 [13].

Given the above, it is known that excess $A \beta$ protein is harmful to the individual. However, it is not yet known the extent of the problems that its accumulation can provide. The transfer of information, from the communication between neurons, is compromised by the excess substance, which culminates in cell death [13]. The tau protein, also accumulated in the described pathology, blocks the transport of essential nutrients for the functions of neurons, causing early cell death.

It is important to highlight the long presymptomatic period between the onset of biochemical changes and the development of clinical symptoms and signs of AD. A study shows patients being diagnosed at age 82 , but with complaints reported 16 years ago [60]. This suggests that the early epidemiological survey makes it possible to monitor the influence of external and internal factors on the trajectory of the decline. Therefore, AD should be suspected in any individual of advanced age, from the age of 65 , who presents a progressive decline in some cognitive domain or impairment in the exercise of their basic functions. The MMSE is still an investigative tool for $\mathrm{AD}$ to check the condition of cognitive functions [61]. The literature already points out other ways of evaluating EFs by neuroimaging that are more accurate. But these techniques are still considered to be expensive.

\section{Neuroimaging technologies and the neural underpinnings of EFs}

With advances in neuroimaging technologies several research studies have been investigate the neural underpinnings of EF. EF has long been associated with the prefrontal cortex (PFC) and involves separable elements of WM, inhibitory control, and set shifting. The substrates of EF have been extensively researched in recent years, spurred by the increased use of neuroimaging techniques normally to developmental psychologists [62].

With neuroimaging techniques would enable the many unanswered questions surrounding the devel- opment of the PFC and the associated cognitive functions to be answered. While methods such as electroencephalography (EEG) and functional magnetic resonance imaging (fMRI) continue to provide many benefits to the developmental researcher, each comes with a set of limiting factors. Advances in functional near-infrared spectroscopy (fNIRS) technology in more recent years have helped to significantly shape the study of the developing brain. One of the three commonly used neuroimaging techniques is EEG. As a non-invasive method of measuring direct electrical activity in the brain, EEG is useful in uncovering the neural underpinnings of cognitive functions. It provides information about functional connectivity between brain regions during cognitive tasks EEG provides information about the size and frequency of a neuronal signal (power). However, the poor spatial resolution of this technology means it is difficult to discriminate the origin of neuronal signals, and so source localization with EEG is not as accurate as with other techniques, such as fMRI.

fMRI records the blood-oxygen-level-dependent (BOLD) response that occurs during neuronal firing. It is offering an indirect measurement of neuronal activity. Its excellent spatial resolution enables researchers to produce images of spatially localized brain activation. Generally, it is expensive. fNIRS is a neuroimaging technique generally used with infant research. fNIRS involves placing a cap containing sources and detectors of near-infrared light on the participant's head [63].

Using fNIRS is possible to measure the changes in concentration of oxygenated and deoxygenated hemoglobin in specific active regions in response to a stimulus. As fNIRS produces better spatial localization than EEG, it allows for more accurate measurement of activity in brain structures associated with behaviors and functions the near-infrared light cannot reach subcortical regions in children and adults. So, fNIRS technology is unable to provide information about the contribution of active subcortical areas [62].

The evidence of a meta-analysis demonstrates the existence of common neural activation across all EF tasks [64]. As a consequence, researchers have been able to measure neural activation that was previously difficult to measure, This, along with the increasing use of age appropriate and well-validated behavioral tasks, has allowed a broadened understanding of EF during early development [62].

Key questions about the development and neural substrates of EF remained unanswered: to what 
extent is the PFC involved in different cognitive functions and their associated behavioral tasks? What other brain regions are involved? What are the different developmental profiles of the neural system that underlies each cognitive function?

About the model of EF, for some researchers' attention may be a necessary first-step towards exhibiting EF skills. Major model of attention proposed by Posner and Rothbart describes an executive attention network as having an important association with $\mathrm{EF}$ parietal areas displayed strong connectivity to lateral/medial frontal areas [65]; areas that have been previously implicated in both the executive attention network and EF [66].

A unified model known as the 'adaptive neural coding framework' was proposed to explain the structure of EF, claiming that EF is a unitary, domaingeneral construct [67]. This function recruits the same specialized frontal pathway (mid-dorsolateral PFC, mid-ventrolateral PFC, and the ACC) in different ways depending on task demands for a range of challenging cognitive tasks.

The frontal and parietal cortices have been identified as core neural substrates of WM from infancy onwards, and subcortical structures have also been shown to be involved note that the connectivity between frontal and parietal cortices, and the network they form, are also important in facilitating the development of WM [68].

Some researchers have put forward the idea that attention may be a necessary first-step towards exhibiting EF skills and many of them describe attentional control as a core component of WM [68]. They also describe an executive attention network as having an important association with EF [62]. The prefrontal cortex undoubtedly still plays a major role in EF across development.

Attention as an EF can be briefly described as the ability to focus on and maintain that focus on a given stimulus while filtering out or ignoring the input being offered by background distractions. Neuroimaging, particularly using positron emission tomography (PET) and fMRI, provides extensive information about neuronal correlates of attention.

Neuroimaging has emerged as a powerful tool for understanding both the neural structure and function of cognitive processes. As such, EF has become a fruitful area of investigation using neuroimaging techniques. Functional imaging methods such as fMRI and PET have shown areas of physiological and metabolic activation during EF tasks (Fig. 1). Structural methods such as MRI and diffusion tensor
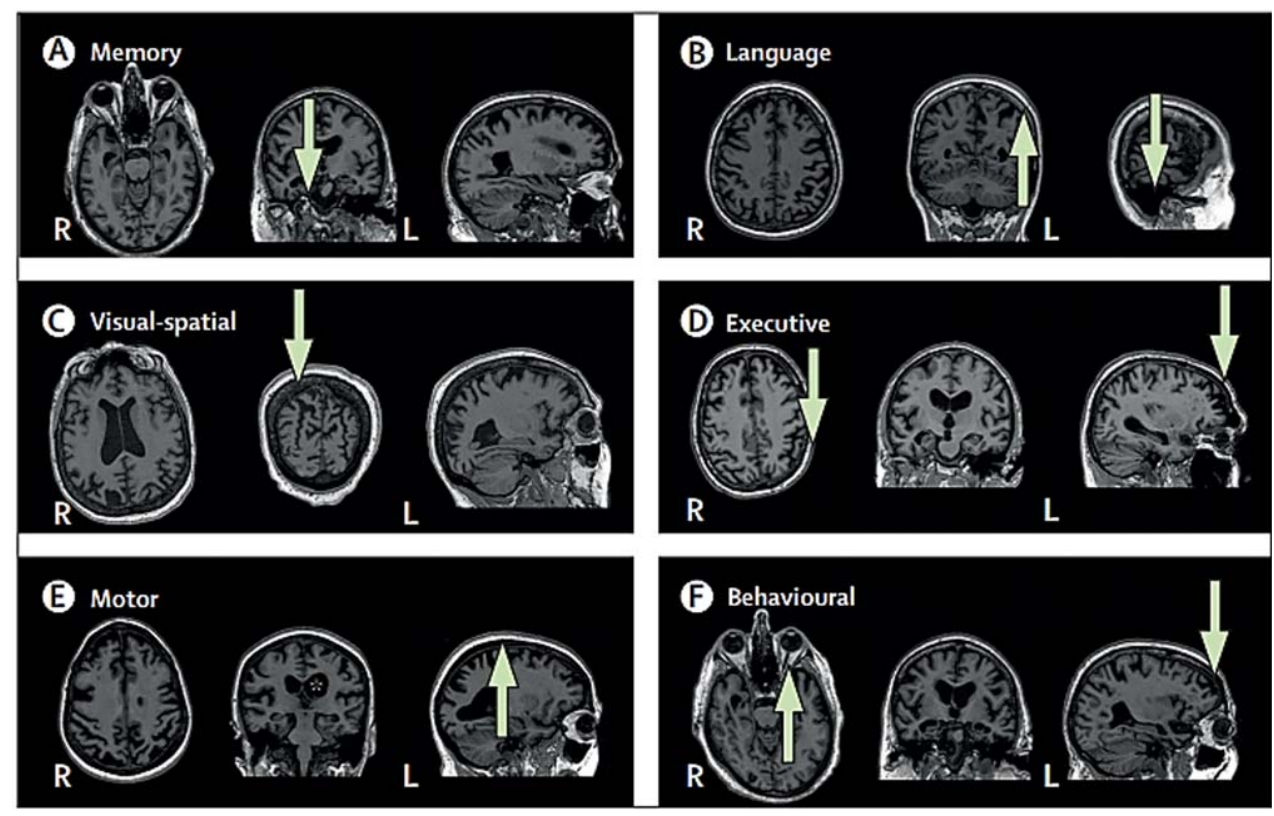

Fig. 1. MRI across Alzheimer's disease phenotypes. A) Memory (typical amnestic); arrow indicates hippocampal atrophy. B) Language (logopenic variant primary progressive aphasia); arrows highlight left temporal-parietal atrophy. C) Visual-spatial (posterior cortical atrophy); arrow indicates parieto-occipital atrophy. D) Executive (also known as dysexecutive); arrows indicate frontoparietal atrophy. E) Motor (corticobasal syndrome); asterisk highlights greater left than right hemisphere atrophy, and arrow indicates atrophy around the motor cortex. F) Behavioral; arrows point to greater temporal than frontal atrophy. R, right; L, left. Reprinted from Lancet Neurology, Vol 20, Graff-Radford et al., New insights into atypical Alzheimer's disease in the era of biomarkers, 222-234, 2021 [69], with permission from Elsevier. 
imaging (DTI) have shown localized areas of volume change or loss of white matter integrity in those who have EF deficits.

Several measures of EF were used. Many studies used a combination of tests or a formal battery though some isolated one test of EF to study. Functional neuroimaging methods (fMRI and PET/SPECT) tended to employ single tests of EF whereas structural methods (MRI, DTI) included multiple tests. On structural MRI, typical AD atrophy begins in the medialtemporal lobe and spreads to the lateral-temporal and parietal cortices. In atypical $\mathrm{AD}$, atrophy is usually most prominent in regions corresponding to clinical symptoms, often sparing the hippocampus early in the disease.

Behavioral research indicates that MCI adults show cognitive deficits in WM, central EF, and attentional resources. Also, cognitive changes are discernible early during AD pathogenesis and MCI. The literature show that the detection of WM deficits through behavioral, functional, and structural changes amongst nonimpaired, MCI, and AD adults.

Region-specific neural activation in response to a memory task is analyzed through neuroimaging techniques including fMRI and PET, as shown in Fig. 2. These neuroimaging methods depict recruitment of specific brain regions during a WM task, demonstrating that activation of the PFC, parietal regions, cingulate gyrus, and hippocampus are associated with WM processing in nonimpaired young adults. These neuroimaging tools allow researchers to compare brain activity during WM tasks of different populations to uncover similarities and contrasts between the selected groups.

MCI is often characterized by slight but noticeable deficits in attention, learning and memory, EF, processing speed, and semantic language. It was previously believed that amnestic MCI had the highest rate of conversion to $\mathrm{AD}$ given the profound episodic memory deficits in $\mathrm{AD}$; however, recent findings suggest that early impairments in visual episodic memory, EF, semantic language/memory, attention, and $\mathrm{WM}$ are also strong predictors of progression from MCI to AD [27].

The earliest pathological changes in $\mathrm{AD}$ can be identify. Using CN elderly from the Alzheimer's Disease Neuroimaging Initiative database, two studies used the discordance between CSF $A \beta_{42}$ levels and florbetapir PET to investigate early stages of $A \beta$ deposition [70] (Fig. 3).

The $A \beta$ deposition may have direct effects on neuronal function and viability. $A \beta$ deposition may
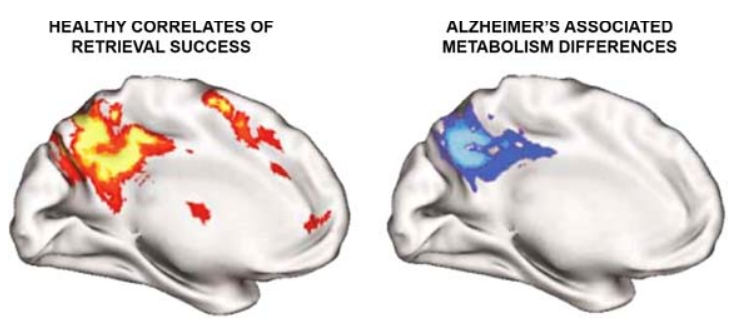

Fig. 2. Correlates of memory retrieval in young adults converge with the same regions that show metabolic change in Alzheimer's disease. (Left) fMRI retrieval success effects are plotted for the medial surface of the cortex, showing regions more active when healthy, young adults correctly remember items from their past. (Right) The correlation between Alzheimer's disease severity and FDG-PET resting glucose metabolism is plotted for a sample of nearly 400 patients. Brighter colors represent regions showing reduced metabolism as the disease becomes more severe. Note the strong correlation between impairment and hypometabolism near precuneus extending into posterior cingulate and retrosplenial cortex. The correspondence is notable, as the retrosplenial cortex has dense reciprocal projections to the hippocampus and parahippocampal gyrus. Retrieval success effects and metabolism differences may thus be reflecting function (Left) and dysfunction (Right) of cortical networks subserving memory. Reprinted from Neuron, Vol 44, Buckner, Memory and executive function in aging and AD: multiple factors that cause decline and reserve factors that compensate, 195-208, 2004 [24], with permission from Elsevier.

facilitate the spread of tau leading to neurodegeneration. $A \beta$ accumulation is believed to be the initial pathology of the most common type of neurological disease leading to dementia, AD. Abnormal levels of $A \beta$ are associated with longitudinal cognitive decline in healthy elderly and progression to $\mathrm{AD}$ dementia in subjects with MCI [71]. Another recourse is a Quick Test of Cognitive Speed (AQT)-color and form score, which is a sensitive test for attention and $\mathrm{EF}$ to account for non-AD specific cognitive impairment. AQT can used alone and as a ratio with the delayed word recall test and MMSE orientation and memory. Also, the studies show predominantly executive EF and relatively spared hippocampal atrophy but widespread cortical atrophy particularly in the parietal lobe.

Recent studies have shown that neuroimage analysis is more reliable and sensitive than traditional cognitive assessment in detecting the presence of early AD [72]. Generally, other forms of cognitive assessment were used too. They analyze different domains of cognition: 1) the MMSE, Alzheimer's Disease Assessment Scale cognitive subscale 13, and Global Clinical Dementia Rating Scale to reflect global cognitive function; 2) the Rey Auditory Verbal Learning Test (RAVLT), including 5-minute layered recall (RAVLT-immediate recall), 30-minute delayed 


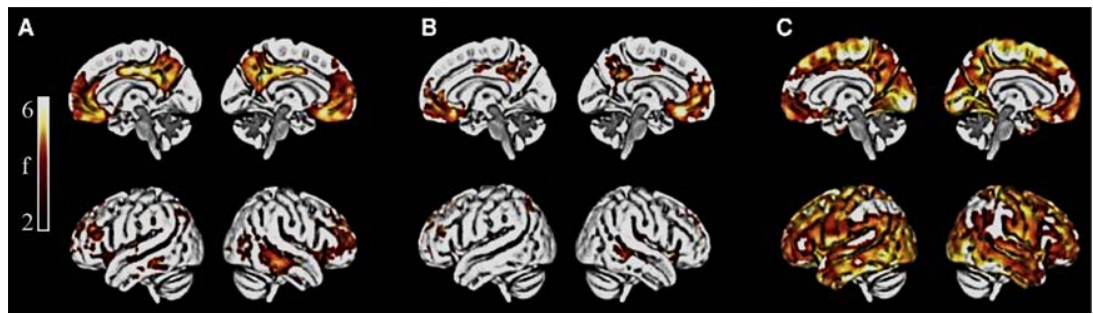

Fig. 3. Regions of $A \beta$ accumulation from longitudinal voxelwise analyses in ADNI. a shows the regions where $A \beta$ fibrils start to accumulate by comparing the annual florbetapir SUVR rate during 2 years between early stage A $\beta$ accumulators (CSF+/PET-, $n=59)$ and nonaccumulators $(\mathrm{CSF}-\mathrm{PET}-, n=218)$. The lateral and medial projections in a show that the most significantly increased accumulation rate among the early $\mathrm{A} \beta$ accumulators was located in the posterior cingulate cortex, the precuneus, and the medial orbitofrontal cortex. $\mathrm{A}$ PET-data-derived ROI of these early-accumulating $A \beta$ regions is available at http://biofinder.se. $\mathbf{b}$ confirms the regions in a without biases from a specific CSF $A \beta_{42}$ cut-off. Here, we performed voxelwise correlations between annual florbetapir SUVR rates and CSF A $\beta_{42}$ levels in A $\beta$ PET negative individuals $(n=277)$. To contrast the early stage $\mathrm{A} \beta$ regions, $\mathbf{c}$ shows the regions with significantly increased annual SUVR rate in late stage $\mathrm{A} \beta$ accumulators $(\mathrm{CSF}+\mathrm{PET}+, n=191)$ compared with non-accumulators (CSF-/PET-). A widespread pattern of $\mathrm{A} \beta$ accumulation is seen in these non-demented CSF+/PET + subjects. Voxelwise two-sample $t$-tests were used and all analyses in a-c are adjusted for age and gender. The significant threshold was set at $p<0.001$. The red and yellow colors illustrate significant $t$ values according to the scale on the left. Reproduced with permission under a Creative Commons Attribution 4.0 International License, from Palmqvist et al., Nat Commun 8, 1214 (2017) [70].

recall (RAVLT-delayed recall), and yes-no recognition (RAVLT-recognition), to reflect memory; 3 ) the Trail Making Test-A and B to reflect attention/EF; 4) animal fluency and the 30-item Boston Naming Task to reflect language function; 5) the Functional Assessment Questionnaire and Neuropsychiatric Inventory to reflect psychosocial function [73].

In short, neuroimaging has emerged as a powerful tool for understanding both the neural structure and function of cognitive processes. So, EF has been investigated too using neuroimaging techniques. Functional imaging methods such as fMRI and PET have shown areas of physiological and metabolic activation during EF tasks. Structural methods such as MRI and DTI have shown localized areas of volume change or loss of white matter integrity in those who have EF deficits (Fig. 4).

\section{METHODS}

The present work fits into an integrative literature review model since it uses a research method that gathers data extracted from a specific search, in an organized way. Such a method is the basis of clinical practice based on scientific evidence (PBE) and allows for a deeper understanding of the researched theme, in addition to presenting the main needs for study and scientific production in each theme [75].

Therefore, for the preparation of the work, the following steps were followed, based on literature [75]: choice of theme and elaboration of the research question; establishment of inclusion and exclusion criteria
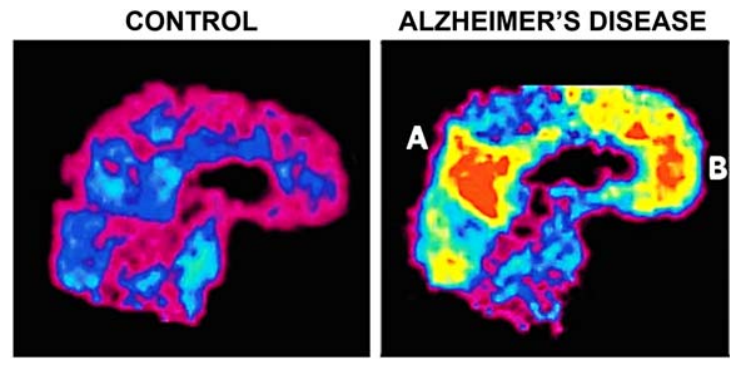

Fig. 4. Amyloid deposition in Alzheimer's disease. PET images of the medial surface show retention of Pittsburg Compound-B (PIB), an amyloid-imaging tracer, in a normal control subject (Left) and an individual with Alzheimer's disease (Right). PIB retention is prominent in posterior parietal regions near posterior cingulate and retrosplenial cortex (A) and in frontal cortex (B). The presence of substantial amyloid burden in posterior regions that overlap memory networks, as shown in Fig. 2, suggests a mechanism by which amyloid toxicity might disrupt memory. Correspondence among regions showing retrieval success effects, metabolism difference in Alzheimer's disease, and amyloid burden extends to lateral parietal regions (data not shown) as well as to measures of cortical atrophy (e.g., see [74]). Reprinted from Neuron, Vol 44, Buckner, Memory and executive function in aging and AD: multiple factors that cause decline and reserve factors that compensate, 195-208, 2004 [24], with permission from Elsevier.

for studies; categorization of selected studies; analysis and interpretation of results; presentation of the review and synthesis of knowledge.

The guiding question presented at the end of the introduction was elaborated from the $\mathrm{PICO} / \mathrm{PIO} / \mathrm{PEO}$ strategy, whose letters indicate: Patient/Problem, Intervention, Comparison, and "Outcomes" (outcome) to PICO; PIO: Population/Problem/Patient, Outcome; PEO: Population/Problem/Patient, Expo- 
sure, Outcome. This strategy allows a complete search on the research platforms, directing the question to obtain keywords that point out answers [76]. Therefore, the guiding question of this study was: What is the impairment of EFs in AD dementia? The next step refers to the crossing of data. For that, an extraction of data from the articles found was carried out, to minimize the obtaining of irrelevant information about the theme in focus. The selected articles, therefore, answered the guiding question, were made available in full and published in the period from 2000 to 2020. The logical Booleans, which include the search details were: ("Alzheimer disease" [MeSH Terms] OR ("Alzheimer" [All Fields] AND "disease" [All Fields]) OR "Alzheimer disease" [All Fields] OR "Alzheimer" [All Fields]) AND ("cognition" [MeSH Terms] OR "cognition" [All Fields] OR ("cognitive" [All Fields] AND "functions" [All Fields]) OR “cognitive functions" [All Fields]) AND ("cognition" [MeSH Terms] OR "cognition" [All Fields]). In all selected databases, the following search keys were used: Alzheimer AND executive functions AND cognition; Alzheimer AND executive functions; Alzheimer AND cognition. The consultation sample was determined using the following inclusion criteria: 1) scientific articles with publication date between 2010 and 2020; 2) scientific articles published in journals with blind peer review; 3) empirical and descriptive articles; 4) the language used was English. In this case, priority was given to articles in the English language; 5) original research and review articles were included, whose theme answered the guiding question.

Studies without specific methodology and which correlated with other diseases or other types of dementia were excluded. To meet the objective, an integrative literature review was adopted. This is a type of review that includes several distinct types of research. This method allows the synthesis of selected studies to be made to draw a panorama about a specific phenomenon. It signals possible gaps and provides a more comprehensive view of knowledge.

The analysis of the integrative review descriptively took place. A comparative table was used for the synthesis of the data, containing the following organization: author, objective, type of study, main results, and conclusions.

The integrative review literature is a method that aims to synthesize results obtained in research on a topic or issue, in a systematic, orderly, and comprehensive manner. A systemic literature review, a well-planned review to answer specific research questions using a systematic methodology and explanation to identify, select, and critically evaluate the results of studies included in the literature review, was also used.

A systematic review attempts to collate all relevant evidence that fits pre-specified eligibility criteria to answer a specific research question. PRISMA was used as a basis for reporting systematic reviews of other types of research. PRISMA-P is intended to guide the development of protocols of systematic reviews and meta-analyses.

\section{RESULTS}

The analysis of the literature data of the integrative review (IRL) was elaborated in a descriptive way. A table was used to extract and synthesize data from each primary study included in the review (Table 1). This chart contains the following information: title, objectives, study design and main findings.

Bibliometric research, based on the search keys applied in each of the databases consulted, resulted in a total of: PubMed - search key - Alzheimer and executive functions and cognition 40,770 articles; PubMed - Alzheimer and executive functions 15,365 articles; PubMed - Alzheimer and cognition 34,569 articles; Science Direct - Alzheimer and executive functions 13,810 articles; Science Direct - Alzheimer and executive functions and cognition 9,068 articles; Science Direct - Alzheimer and cognition 29773 articles; Web of Science - Alzheimer and executive functions 2,114 articles; Web of Science - Alzheimer and executive functions and cognition 878 articles; Web of Science - Alzheimer and executive functions 2,841 articles; Web of Science - Alzheimer and cognition 8,486 articles. The data indicate that there is a greater presence of articles involving the theme in the PubMed database, probably because it is a database more focused on the medical field. It was observed that the most refined search took place in: Alzheimer and executive functions, with fewer articles, but with a greater degree of precision and utilization.

Figure 5 shows PRISMA protocol used to describe quantitatively the selected studies by the inclusion and exclusion criteria.

When associated with the Cognition search key, the number of findings is greater because it involves a broader theme. Alzheimer's keys and executive functions allow for more refined targeting.

The search also indicated that there have been numerous studies on the subject in the last ten years, 
Table 1

Integrative review literature in chronological order

\begin{tabular}{|c|c|c|c|}
\hline Citation/Year & Objective & Type of study & Main findings \\
\hline Lezak (1982) [8] & $\begin{array}{l}\text { Describe that EFs are important to detect the proper } \\
\text { functioning of the cognitive system }\end{array}$ & $\begin{array}{l}\text { Descriptive } \\
\text { study }\end{array}$ & $\begin{array}{l}\text { EFs are essential for independent, creative, and socially constructive behavior. EFs } \\
\text { comprise the mental capacities needed to formulate goals, plan how to achieve } \\
\text { them and execute plans effectively. }\end{array}$ \\
\hline Lezak (1982) [8] & Show the capabilities of EFs & $\begin{array}{l}\text { Descriptive } \\
\text { study }\end{array}$ & $\begin{array}{l}\text { EFs are crucial to normal behavior. Although they tend to be vulnerable to brain } \\
\text { damage, they are often overlooked in neuropsychological and neurological } \\
\text { examinations. Reasons why there are few formalized examination procedures for } \\
\text { assessing EFs. }\end{array}$ \\
\hline McKhann et al. (1984) [19] & $\begin{array}{l}\text { Propose criteria that can serve as a guide for the } \\
\text { diagnosis of AD. }\end{array}$ & $\begin{array}{l}\text { Descriptive } \\
\text { study }\end{array}$ & $\begin{array}{l}\text { Medical criteria for diagnosing AD include insidious onset and progressive } \\
\text { impairment of memory and other cognitive functions. There are no motor, sensory } \\
\text { or coordination deficits at the beginning of the disease. The diagnosis cannot be } \\
\text { determined by laboratory tests. These tests are especially important in identifying } \\
\text { other probable causes of dementia that must be ruled out before the diagnosis of } \\
\text { AD. }\end{array}$ \\
\hline McKhann et al. (1984) [19] & $\begin{array}{l}\text { Address medical history, clinical examination, } \\
\text { neuropsychological testing, and laboratory } \\
\text { assessments }\end{array}$ & $\begin{array}{l}\text { Descriptive } \\
\text { study }\end{array}$ & $\begin{array}{l}\text { Neuropsychological tests provide confirmatory evidence of the diagnosis of } \\
\text { dementia and help to assess the course and response to therapy. }\end{array}$ \\
\hline Posner et al. (1992) [6] & Show that cognition is a computational process & $\begin{array}{l}\text { Descriptive } \\
\text { study }\end{array}$ & $\begin{array}{l}\text { Cognition involves all the processes by which input is transformed, reduced, } \\
\text { worked out, stored, retrieved, and used. }\end{array}$ \\
\hline Cipolotti \& Warrington (1995) [12] & $\begin{array}{l}\text { Provide an overview of the main methods for } \\
\text { assessing cognitive function and an outline of what } \\
\text { can promote a European assessment. }\end{array}$ & $\begin{array}{l}\text { Descriptive } \\
\text { study }\end{array}$ & $\begin{array}{l}\text { Patients with brain problems have deficiencies in memory, language, perception, } \\
\text { thinking, action, and other functions. }\end{array}$ \\
\hline Stern (2002) [20] & $\begin{array}{l}\text { Develop a coherent theoretical explanation of the } \\
\text { cognitive reserve }\end{array}$ & $\begin{array}{l}\text { Descriptive } \\
\text { study }\end{array}$ & $\begin{array}{l}\text { The concept of reserve is highly relevant for investigating variability in individual } \\
\text { performance and for understanding how the brain responds to challenges and } \\
\text { pathologies. }\end{array}$ \\
\hline Baddeley \& Wilson (2002) [45] & $\begin{array}{l}\text { Studying an episodic buffer to determine whether } \\
\text { the pattern of results reported [45] generalizes other } \\
\text { samples of organic amnesia }\end{array}$ & $\begin{array}{l}\text { Experimental } \\
\text { study }\end{array}$ & $\begin{array}{l}\text { It is possible that the WMS immediate recall of the logical memory passage } \\
\text { exceeds what is available in the episodic buffer and is driven by what is } \\
\text { remembered from the long-term episodic memory. }\end{array}$ \\
\hline Alcorn \& Washburn (2003) [3] & $\begin{array}{l}\text { Present that cognition concerns a series of mental } \\
\text { functions. }\end{array}$ & $\begin{array}{l}\text { Descriptive } \\
\text { study }\end{array}$ & $\begin{array}{l}\text { Cognition comprises faculties such as memory and thought, among others, and } \\
\text { emotions. }\end{array}$ \\
\hline Buckner (2004) [24] & $\begin{array}{l}\text { Show the physiological changes that cause memory } \\
\text { decline. }\end{array}$ & $\begin{array}{l}\text { Descriptive } \\
\text { study }\end{array}$ & The decline in memory in aging arises from multiple processes associated with age. \\
\hline Brandimonte et al. (2006) [2] & Attest that cognition comes from representation & $\begin{array}{l}\text { Descriptive } \\
\text { study }\end{array}$ & Studies on cognition reveal a correlation with the act of processing data. \\
\hline Bottino et al. (2006) [14] & $\begin{array}{l}\text { To present studies on dementias and } \\
\text { neuropsychiatric disorders in the elderly. Improve } \\
\text { behaviors and practices in geriatric neuropsychiatry }\end{array}$ & $\begin{array}{l}\text { Descriptive } \\
\text { study }\end{array}$ & $\begin{array}{l}\text { The diagnosis of dementia is made considering memory deficit and another } \\
\text { cognitive function associated with social and occupational impairment. Diagnosis } \\
\text { requires assessment of cognitive abilities. }\end{array}$ \\
\hline Jack et al., 2010 [17] & $\begin{array}{l}\text { Propose a model that relates the stage of the disease } \\
\text { to the biomarkers of AD. Provide a framework for } \\
\text { testing hypotheses that relates the temporal changes } \\
\text { in AD biomarkers to the clinical stage of the disease } \\
\text { and to each other }\end{array}$ & $\begin{array}{l}\text { Experimental } \\
\text { study }\end{array}$ & $\begin{array}{l}\text { The temporal relationships between biomarkers and the clinical stage of the } \\
\text { disease constitute a series of testable hypotheses. }\end{array}$ \\
\hline
\end{tabular}


Table 1

(Continued)

\begin{tabular}{|c|c|c|c|}
\hline Citation/Year & Objective & Type of study & Main findings \\
\hline Van der Elst et al., 2011 [44] & $\begin{array}{l}\text { Establish the normal range of performance in AVF } \\
\text { and DF tests }\end{array}$ & $\begin{array}{l}\text { Experimental } \\
\text { study }\end{array}$ & $\begin{array}{l}\text { The scores of the structured tests AVF and DF increased linearly as a function of } \\
\text { age, while the relationship between age and the scores of the unstructured DF test } \\
\text { was curvilinear (that is, the improvement in the test scores was much more } \\
\text { pronounced for younger children than for older children) }\end{array}$ \\
\hline Diamond (2012) [10] & $\begin{array}{l}\text { It describes that EFs comprise inhibition, inhibitory } \\
\text { control, including self-control and selective } \\
\text { attention and collective inhibition, WM, and }\end{array}$ & $\begin{array}{l}\text { Observational } \\
\text { study }\end{array}$ & EFs can also be considered as executive control \\
\hline
\end{tabular}

Thies \& Bleiler (2012) [13] $\quad \begin{aligned} & \text { cognitive flexibility. } \\ & \text { Define dementia. and providing information to }\end{aligned}$ increase understanding of the impact of $\mathrm{AD}$ on public health. Topics covered include incidence, prevalence, mortality rates, health care costs and costs of care and effect on caregivers and society. The report also explores the problems that arise when people with $\mathrm{AD}$ and other dementias live alone. The characteristics, risks and unmet needs of this population are described.

Stopford et al. (2012) [37]
Compare WM, attention, and executive testing
performance in AD patients (a 'typical' group with performance in AD patients (a 'typical' group with
early onset with memory deficits, perceptual-spatial language and function and an "amnesic" group) and frontotemporal dementia

Reinvang et al. (2012) [39] Indicate that, in a relatively young population of $\mathrm{MCI}$, investigated with comprehensive neuropsychological tests, eMCI is a common variant.

Fiore et al. (2012) [42]

Descriptive

study

$\mathrm{AD}$ involves nerve cell death in some areas and loss of cognitive functions. information on verbal and visuospatial memory tasks.

Present normative data for STM and WM verbal and visuospatial tasks for a sample of mentally and physically healthy elderly
Experimental study

Observationa

study

Descriptive

study

Experimental study

The study confirmed earlier findings of impaired WM, attention, and executive task performance in $\mathrm{AD}$. The data highlight the prominence of $\mathrm{WM}$ deficits in early $\mathrm{AD}$, confirming that they are a prominent symptom

In the identification of brain changes underlying eMCI (impairment in EFs), fiber integrity should be emphasized as measured with DTI, as well as the cortical thinning of the frontal lobe.

The performance of the participants was higher in the verbal task than in the visuospatial one. However, regardless of the task domain, an age-related decline in update performance was found. In addition, the analysis of the serial positions suggested that, in the update procedure, the participants were not actively trying to maintain the items, preferring to adopt a low effort strategy, "based on recency". The use of this type of strategy is more evident in older participants, as demonstrated both in the accuracy performance and in the proportion of intrusion errors.

The data reveal the main effects of age, level of education and gender on STM and WM performance of OA. Equation-based normalization can therefore be used to take these factors into account. The results provide a set of cutoff scores for five standardized tasks that can be used to determine the presence of STM disability or WM in the elderly. 
Chaney (2013) [1]

Bender \& Beller (2013) [5

Uehara et al. (2013) [11]

Cohen et al. (2013) [40]

Rahimi \& Kovacs (2014) [22]

Silva (2014) [25]

Silva (2014) [26]

Karr et al. (2018) [9]

Verlinde et al. (2015) [60]

Kirova et al. (2015) [27]

Rabinovici et al. (2015) [41]
Compare WM, attention, and executive testing performance in AD patients (a 'typical' group with early onset with memory deficits, perceptual-spatial language and function and an "amnesic" group) and frontotemporal dementia

Indicate the history of cognition and its origin

Point out how culture can affect cognitive processes in many ways, based on instances of numerical

cognition, ethnobiological reasoning, and theory of mind.

Evidence of divergences in the definition of $\mathrm{EF}$,

review and point out the main theories and models, in addition to classic approaches that influenced the definition of the concept of EF.

Review studies on incidental self-control in three domains: affect, behavior, and pain. Among them, we researched studies using a variety of

experimental paradigms, including affection labeling, emotional expression interference, threat to intimate relationships, visual masking, and placebo manipulations.

Show the prevalence of mixed brain pathologies reported in recent studies.

Demonstrate the influence of memory on the reading of patients with $\mathrm{AD}$

Demonstrate that the priming effect is maintained during AD.

Apply performance-based tests of EFs and re-analyze summary data to identify best fit models

Investigate trajectories of cognition and daily functioning in preclinical dementia

Analyze the decline in WM through normal aging,

$\mathrm{MCI}$, and $\mathrm{AD}$ to highlight the behavioral and

neurological differences that distinguish these three stages to guide future research on MCI diagnosis, cognitive therapy, and AD prevention

Review the executive / attention deficiency as an important aspect of MCI or pre-MCI in terms of symptom manifestation and importance for disease progression
Experimental

study

Descriptive

study

Descriptive

study

Descriptive

study

Descriptive

study

Self-control is like a muscle and can be tired (or trained) in several domains (for a review, see [77]), literary neuroimaging structure commonly points to the involvement of rVLPFC in many different forms of self-control.

Observational study

Observational study

Observational

and

experimental

study

Experimental

study

Experimental

study

Descriptive

study

Descriptive

study

The data highlight the prominence of WM deficits in early-onset $\mathrm{AD}$, confirming that they are a prominent symptom of these patients, and dissociable from classic amnesia traditionally associated with $\mathrm{AD}$. The results point to the need for caution in assuming that the impaired performance in AD in tests of WM and attention necessarily imply a central executive commitment to frontal lobe substrate. Cognition comes from the Middle Ages

Internal cognitive processes are affected by culture-specific external representations; they are affected by the culture-dependent content to be processed; and are affected more generally by people's cultural backgrounds.

The EFs can be seen as a prism, which can be seen through its countless faces, from its various angles. In contrast, there is no consensus on a formal definition.

The results show some evidence of greater one-dimensionality of the EF anong samples

The incident dementia has a long preclinical trajectory of decline in cognition and daily functioning, which already begins 16 years before the clinical diagnosis.

OA have less WM capacity than YA.

In a relatively young population of MCI investigated with comprehensive neuropsychological tests, eMCI is a common variant. Dysfunctions may remain undetected, even if a complete neuropsychological examination is performed. 
Table 1

(Continued)

\begin{tabular}{ll}
\hline Citation/Year & \multicolumn{1}{c}{ Objective } \\
\hline Faria et al. (2015) [47] & $\begin{array}{l}\text { To present a systematic review of the most used } \\
\text { instruments for assessing EFs in elderly people with } \\
\text { distinct levels of education in clinical and } \\
\text { experimental research. }\end{array}$ \\
De Houwer et al. (2016) [4] & $\begin{array}{l}\text { Point out that within cognitive psychology, } \\
\text { cognition is typically defined in terms of } \\
\text { information processing. And within functional } \\
\text { psychology, cognition is conceptualized in terms of } \\
\text { behavior. Next, we point out that both perspectives } \\
\text { are not mutually exclusive. }\end{array}$
\end{tabular}

Blanco Martin et al. (2016) [35] Demonstrate that EF is present in aMCI and whether low scores on $\mathrm{EF}$ tests are related to progression to $\mathrm{AD}$ or other type of dementia

Apostolova (2016) [38] Discuss recent advances in the diagnosis and treatment of $\mathrm{AD}$.

Descriptive

study

Descriptive
study

study

Experimental

study

Descriptive

study

Present the effectiveness of the treatment and

development of new drugs. In this study, we present the first acetylcholine/ oxygen hybrid enzymatic fuel cell for self-powered detection at the acetylcholine plasmid site, which is based on the combination of an enzymatic anode with a Pt cathode.

Karr et al. (2018) [9]

Cacciaglia et al., 2018 [34]

Summarize confirmatory factor analysis in tests based on the performance of EFs and reanalyze the summary data to identify the most appropriate models.

Perform an unbiased voxel analysis of the associations between regional GMV and WMV and performance in both cognitive domains in a sample of 463 individuals

Caccigllia et al. 2018 [34] To determine the structural correlates of the brain of EM and EFs in cognitively healthy middle-aged individuals, analyzing GMV and WMV, using an impartial total cerebral voxel approach

Experimental study

Experimental study

Type of study

Main findings

five years by research groups around the world to assess the elderly. These results can guide future research and assist in the construction of evaluation protocols for the evaluation of EFs, considering the distinct levels of education and

sociodemographic profiles of the elderly in Brazil.

Cognition has a procedural character

The variability in their morphological properties, and not just in their activation patterns, affects EM and EFs, respectively. Aging reverses these associations and supports previously advanced theories of cognitive neurodevelopment.

Larger regions of the brain are typically associated with greater processing capacity and, consequently, lead to a better performance of the functions they mediate [78]. In addition, it would be expected to find larger volumes predicting better memory performance, given the close relationship between cognitive decline and cerebral atrophy observed in patients with $\mathrm{AD}$, as well as in normal aging.
Dysexecutive syndrome is a broad concept that is not limited to the frontal lobes negative impact on the patient's autonomy and can have prognostic value. Although it is now possible to diagnose AD in the initial stages and even in the pre-symptomatic stages, we still lack preventive drugs or disease modifiers that can alter its course. The effect of AD on individual patients and their families and

provide a potentially attractive alternative to established methods that require laborious and time-consuming sample treatments and expensive instruments

The constructions most often represented in published EF measurement models include inhibition, update/WM, and displacement. 
Sørensen \& Nielsen et al. 2018 [61] Use a set of SVMs that combine packaging with replacement and feature selection. SVM is the most used algorithm for multivariate classification of dementia.

Harvey (2019) [7]

Wennberg et al. (2019) [23]

Abufalia et al., 2019 [31]

Delpak \& Talebi (2020) [15]

Stern et al. (2020) [21]

Hunter et al. (2020) [30]

Amanzio et al. (2020) [33]

Eyigoz et al. (2020) [46]
Defend the idea that cognitive performance is

typically conceptualized in terms of functioning domains. These domains are hierarchical

Investigate whether pathologies are associated with cognitive and motor ante-mortem function,

depression, magnetic resonance volumetric

measurements or apolipoprotein.

Show that O-LOAD can exhibit reduced executive performance evidenced by increased errors and reduced strategy use in an episodic memory task.

To evaluate the relationship between seven areas of cognitive function in the MMSE test with age, gender, and education level.

Develop consensus definitions for cognitive reserve, cerebral reserve, and brain maintenance. Evaluate measures used to implement these concepts in research environments and develop guidelines for research that explore or use these concepts.

Compare the balance between people with $\mathrm{AD}$, healthy OA and healthy YA and 2) to quantify the interaction of visual acuity and EF in postural stability.

This study focuses on reducing self-awareness in neurological disorders, such as $\mathrm{AD}$, behavioral frontotemporal dementia and acquired brain injuries. Use classification methods to predict the future onset of $\mathrm{AD}$ in cognitively normal individuals through automated linguistic analysis.
Experimental

study

Descriptive Cognitive functions are interconnected in domains.

study

Experimental study

Some pathologies related to dementia are associated with worse performance in clinical measures and cerebral atrophy in intact elderly people

Experimental study

Observed memory difficulties may be partly associated with executive deficits, suggesting an interaction between memory and EFs. Losses in process scores were observed before the clinical decline in neuropsychological scores in this risk cohort and can be useful cognitive markers of preclinical LOAD.

Descriptive According to the other results, aging, female gender, and lower educational level study cause patients to get lower scores on the MMSE test

Research involving cognitive reserve should note the inclusion of three components - the state of the brain (reflecting brain change or pathology), result of clinical or cognitive performance: a socio-behavioral proxy (i.e., an index of exposure over life / pre-morbid capacity) a functional brain measurement.

Experimental Individuals with poorer visual acuity had worse EF, and those with poorer EF had study poorer balance control. These results highlight the importance of assessing not only vision and balance, but also EF, especially in elderly people with $\mathrm{AD}$.

Descriptive study

Executive metacognitive dysfunction and impaired MPFC, outlined through the neurocognitive model, can help to understand how the central executive system can contribute to AD-related self-awareness disorders

Experimental It is possible to predict the future onset of AD using language samples obtained study from cognitively normal individuals.

AD, Alzheimer's disease; aMCI, amnestic mild cognitive impairment; AVF, Animal Verbal Fluency; DF, Design Fluency; DTI, diffusion tensor imaging; EF, executive function; EM, episodic memory; eMCI, early mild cognitive impairment; GMV, gray matter volume; LOAD, late onset Alzheimer's disease; MCI, mild cognitive impairment; MMSE, Mini-Mental State Examination; MPFC, medial prefrontal cortex; O-LOAD, offspring of patients with LOAD; OA, older adults; rVLPFC, right ventrolateral prefrontal cortex; STM, short-term memory; SVMs, support vector machines; WM, working memory; WMS, Wechsler Memory Scale; WMV, white matter volume; YA, young adults. 
PRISMA 2009 Flow Diagram

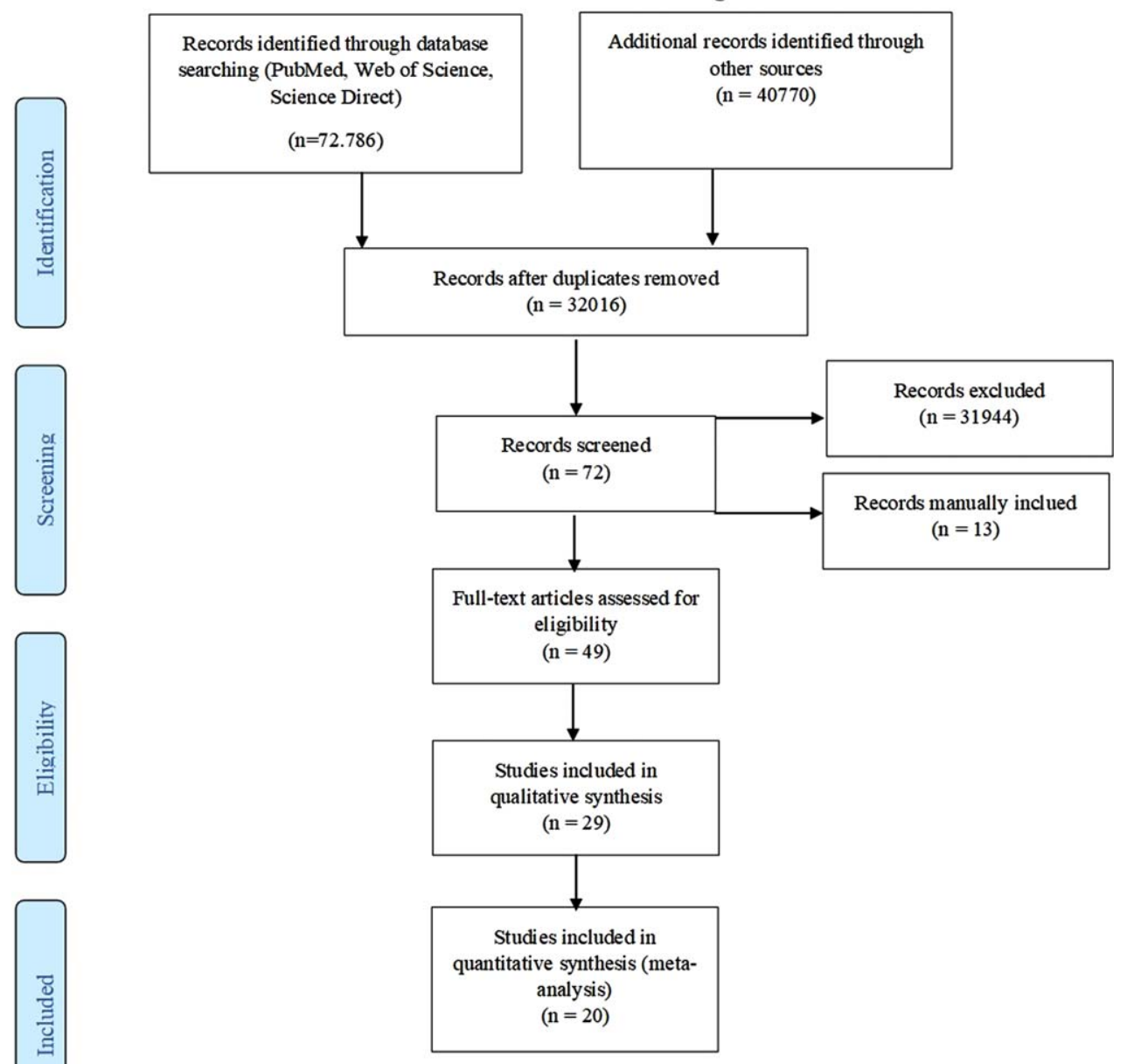

Fig. 5. PRISMA 2009 flow diagram. Source: Moher et al., 2009 [79].

which suggests that there are still discussions and gaps to be filled. It was observed that the theme involves several elements of human cognition, which makes the complex subject surrounded by interface investigations.

More recent studies have pointed out a greater concern with the correlation between attention and Alzheimer's regarding the involvement of EFs in the presence of $\mathrm{AD}$, which suggests a need for investigation of future works to deepen these questions. The articles were selected according to the criteria established in the methodology chapter.

\section{DISCUSSION}

With the studies it is possible to conclude that the EFs make up the diagnostic evaluation of $\mathrm{AD}$, being still well discussed in the literature. There was no evidence of modification of application and content of analysis of EFs. The MMSE is still widely used as one of the analysis resources.

The results also demonstrate that the EF tasks used in addition to the screening tool, the MMSE, enabled to distinguish the difference between the average score of the AD group as opposed to another groups. In future research prospects lies the need using an efficient method for the early screening of $\mathrm{AD}$ and accessible.

For a long time, EFs have created a lot of interest by their simplicity and the attractiveness of their discriminatory efficiency for the different dementia states, from early to advanced stage. It would be interesting to combine the tests with which it was possible to distinguish the groups studied to verify 
their discriminating power in a battery combining them.

The literature points out that there is a lot of complexity around EFs, including controversies, so much so that it concerns the nomenclature, as well as the way of investigating elements such as attention and $\mathrm{WM}$ in the analysis of EFs, a lot due to the complexity that involves them.

In more recent studies, there is a greater concern for attention, leading to believe in the review made in this study that it is one of the most evident elements in $\mathrm{AD}$, in addition to $\mathrm{WM}$, which deserves further investigation in research future. It was also observed that all selected studies pointed to the impairment of $\mathrm{EFs}$ in $\mathrm{AD}$ and that the cognitive elements considered are not isolated, but there is a correlation between them, regarding cognitive functional dependence.

\section{ACKNOWLEDGMENTS}

We would like to offer our special thanks to the Federal University of Itajubá, Federal University of Ouro Preto, and Federal University of Rio Grande do Norte.

\section{FUNDING}

This study was not funded.

\section{CONFLICT OF INTEREST}

The authors have no conflict of interest to report.

\section{REFERENCES}

[1] Chaney DW (2013) An overview of the first use of the terms cognition and behavior. Behav Sci (Basel) 3, 143-153.

[2] Brandimonte, MA, Bruno N, Collina S (2006) Cognition. In Psychological concepts: An international historical perspective, $1^{\text {st }}$ ed, Pawlik K, d'Ydewalle G, eds. Taylor \& Francis, London, UK.

[3] Alcorn MB, Washburn AM (2003) Cognitive psychology. In Magill's Encyclopedia of Social Science: Psychology, Vol. $1,2^{\text {nd }}$ ed, Piotrowskim NA, Irons-Georges T, eds. Salem Press, Pasadena, CA.

[4] De Houwer J, Barnes-Holmes D, Barnes-Holmes Y (2016) What is cognition? A functional-cognitive perspective. Based on: Hays SC, Hofmann SG, eds. Core Processes of cognitive behavioral therapies. Harbinger, Oakland, CA. https://www.researchgate.net/publication/308749950_What is_Cognition_A_FunctionalCognitive_Perspective\#fullText FileContent. Accessed February 6, 2021.

[5] Bender A, Beller S (2013) Cognition is... fundamentally cultural. Behav Sci (Basel) 3, 42-54.

[6] Posner M. I, Bourke P, Neisser U (1992) Cognitive psychology. Am J Psychol 105, 621-626.
[7] Harvey P (2019) Domains of cognition and their assessment. Dialogues Clin Neurosci 21, 227-237.

[8] Lezak, MD (1982) The problem of assessing executive functions. Int J Psychol 17, 281-297.

[9] Karr JE, Areshenkoff CN, Rast P, Hofer SM, Iverson GL, Garcia-Barrera MA (2018) The unity and diversity of executive functions: A systematic review and re-analysis of latent variable studies. Psychol Bull 144, 1147-1185.

[10] Diamond A (2012) Executive functions. Ann Rev Psychol 64, 135-168.

[11] Uehara H, Charchat-Fichman, H, Landeira-Fernandez J (2013) Funções executivas: Um retrato integrativo dos principais modelos e teorias desse conceito. Rev Neuropsicol Latinoamericana 5, 25-37.

[12] Cipolotti L, Warington EK (1995) Neuropsychological assessment. J Neurol Psychiatry 58, 655-664.

[13] Thies W, Bleiler L (2012) Alzheimer's disease facts and figures. Alzheimers Dement 8, 131-168.

[14] Bottino C, Lals J, Blay SL (2006) Demência e transtornos cognitivos em idosos. Guanabara Koogan, Rio de Janeiro.

[15] Delpak A, Talebi M (2020) On the impact of age, gender, and educational level on cognitive function in Alzheimer's disease: A quantitative approach. Arch Gerontol Geriatr 89, 104090.

[16] Yao T, Sweeney E, Nagorski J, Shulman JM, Allen GI (2020) Quantifying cognitive resilience in Alzheimer's disease: The Alzheimer's Disease Cognitive Resilience Score. PLoS One 15, e0241707.

[17] Jack CR Jr, Knopman DS, Jagust WJ, Shaw LM, Aisen PS, Weiner MW, Petersen RC, Trojanowski JQ (2010) Hypothetical model of dynamic biomarkers of the Alzheimer's pathological cascade. Lancet Neurol 9, 119-128.

[18] Melo DM, Barbosa AJG (2015) O uso do Mini-Exame do Estado Mental em pesquisas com idosos no Brasil: Uma revisão sistemática. Cien Saude Colet 20, 3865-3876.

[19] McKhann G, Drachman D, Folstein M, Katzman R, Price D, Stadlan EM (1984) Clinical diagnosis of Alzheimer's disease: Report of the NINCDS-ADRDA Work Group under the auspices of Department of Health and Human Services Task Force on Alzheimer's Disease. Neurology 34, 939-944.

[20] Stern Y (2002) What is cognitive reserve? Theory and research application of the reserve concept. J Int Neuropsychol Soc 8, 448-460.

[21] Stern Y, Arenaza-Urquijo EM, Bartrés-Faz D, Belleville S, Cantilon M, Chetelat G, Ewers M, Franzmeier N, Kempermann G, Kremen WS, Okonkwo O, Scarmeas N, Soldan A, Udeh-Momoh C, Valenzuela M, Vemuri P, Vuoksimaa E; the Reserve, Resilience and Protective Factors PIA Empirical Definitions and Conceptual Frameworks Workgroup (2020) Whitepaper: Defining and investigating cognitive reserve, brain reserve, and brain maintenance. Alzheimers Dement 16, 1305-1311.

[22] Rahimi J, Kovacs GG (2014) Prevalence of mixed pathologies in the aging brain. Alzheimers Res Ther $\mathbf{6}, 82$.

[23] Wennberg AM, Whitwell JL, Tosakulwong N, Weigand SD, Murray ME, Machulda MM, Petrucelli L, Mielke MM, Jack CR Jr, Knopman DS, Parisi JE, Petersen RC, Dickson DW, Josephs KA (2019) The influence of tau, amyloid, alphasynuclein, TDP-43, and vascular pathology in clinically normal elderly individuals. Neurobiol Aging 77, 26-36.

[24] Buckner RL (2004) Memory and executive function in aging and $\mathrm{AD}$ : Multiple factors that cause decline and reserve factors that compensate. Neuron 44, 195-208.

[25] Silva PCD (2014) Alzheimer, memória e leitura. D’Plácido, Belo Horizonte. 
[26] Silva PCD (2014) A influência do efeito priming e estimulação cognitiva para a leitura oral de textos em idosos com doença de Alzheimer. Revista do Sell 4, 1-21.

[27] Kirova AM, Bays RB, Lagalwar S (2015) Working memory and executive function decline across normal aging, mild cognitive impairment, and Alzheimer's disease. Biomed Res Int 2015, 748212.

[28] Sachdev PS, Lipnicki DM, Crawford J, Reppermund S, Kochan NA, Trollor JN, Wen W, Draper B, Slavin MJ, Kang K, Lux O, Mather KA, Brodaty H; Sydney Memory, Ageing Study Team (2013) Factors predicting reversion from mild cognitive impairment to normal cognitive functioning: A population-based study. PLoS One 8, e59649.

[29] Guarino A, Favieri F, Boncompagni I, Agostini F, Cantone M, Casagrande M (2019) Executive functions in Alzheimer disease: A systematic review. Front Aging Neurosci 15, 437.

[30] Hunter SW, Divine A, Madou E, Omana H, Hill KD, Johnson AM, Holmes JD, Wittich W (2020) Executive function as a mediating factor between visual acuity and postural stability in cognitively healthy adults and adults with Alzheimer's dementia. Arch Gerontol Geriatr 89, 104078.

[31] Abulafia C, Fiorentini L, Loewenstein DA, Curiel-Cid R, Sevlever G, Nemeroff CB, Villarreal MF, Vigo DE, Guinjoan SM (2019) Executive functioning in cognitively normal middle-aged offspring of late-onset Alzheimer's disease patients. J Psychiatr Res 112, 23-29.

[32] Baggeta P, Alexander P (2016) Conceptualization and operationalization of executive function. Mind Brain Educ 10, 10-33.

[33] Amanzio M, Bartoli M, Cipriani GE, Palermo S (2020) Executive dysfunction and reduced self-awareness in patients with neurological disorders. A mini-review. Front Psychol 11, 1697.

[34] Cacciaglia R, Molinuevo JL, Sánchez-Benavides G, Falcón C, Gramunt N, Brugulat-Serrat A, Grau O, Gispert JD; ALFA Study (2018) Episodic memory and executive functions in cognitively healthy individuals display distinct neuroanatomical correlates which are differentially modulated by aging. Hum Brain Mapp 39, 4565-4579.

[35] Blanco Martín E, Ugarriza Serrano I, Elcoroaristizabal Martín X, Galdos Alcelay L, Molano Salazar A, Bereincua Gandarias R, Inglés Borda S, Uterga Valiente JM, Indakoetxea Juanbeltz MB, Moraza Lopez J, Barandiarán Amillano M, Fernández-Martínez M (2016) Dysexecutive syndrome in amnesic mild cognitive impairment: A multicenter study. BMC Neurol 16, 88.

[36] Malhorta, PA (2019) Impairments of attention in Alzheimer's disease. Curr Opin Psychol 29, 42-48.

[37] Stopford CL, Thompson JC, Neary D, Richardson AM, Snowden JS (2012) Working memory, attention, and executive function in Alzheimer's disease and frontotemporal dementia. Cortex 48, 429-446.

[38] Apostolova LG (2016) Alzheimer disease. Continuum (Minneap Minn) 22, 419-434.

[39] Reinvang I, Grambaite R, Espese T (2012) Executive dysfunction in MCI: Subtype or early symptom. Int $J$ Alzheimers Dis 2012, 936272.

[40] Cohen JR, Berkman ET, Lieberman MD (2013) Intentional and incidental self-control in ventrolateral prefrontal cortex. In Principles of Frontal Lobe Function. $2^{\text {nd }}$ ed, Stuss D. T, Knight RT, eds. Oxford University Press, pp. 417-440.

[41] Rabinovici GD, Stephens ML, Possin KL (2015) Executive dysfunction. Continuum (Minneap Minn) 21 (3 Behavioral Neurology and Neuropsychiatry), 646-659.
[42] Fiore F, Borella E, Mammarella IC, De Beni R (2012) Age differences in verbal and visuo-spatial working memory updating evidence from analysis of serial position curves. Memory 20, 14-27.

[43] Fournet N, Roulin JL, Vallet F, Beaudoin M, Agrigoroaei S, Paignon A, Dantzer C, Desrichard O (2012) Evaluating short-term and working memory in older adults: French normative data. Aging Ment Health 16, 922-930.

[44] Van der Elst W, Hurks P, Wassenberg R, Meijs C, Jolles J (2011) Animal Verbal Fluency and Design Fluency in school-aged children: Effects of age, sex, and mean level of parental education, and regression-based normative data. J Clin Exp Neuropsychol 33, 1005-1015.

[45] Baddeley A, Wilson BA (2002) Prose recall and amnesia: Implications for the structure of working memory. $\mathrm{Neu}$ ropsychologia 40, 1737-1743.

[46] Eyigoz E, Mathur S, Santamaria M, Cecchi G, Naylor M (2020) Linguistics markers predict onset of Alzheimer's. EClinicalMedicine 28, 100583.

[47] Faria CA, Alves HVD, Charchat-Fichman H (2015) The most frequently used tests for assessing executive functions in aging. Dement Neuropsychol 9, 149-155.

[48] McKhann G, Drachman D, Folstein M, Katzman R, Price D, Stadlan EM (1984) Clinical diagnosis of Alzheimer's disease. Report of the NINCDS-ADRDA Work Group under the auspices of Department of Health and Human Services Task Force on Alzheimer's Disease. Neurology 34, 939-944.

[49] Moreira FTC, Sale MG, Di Lorezno M (2017) Towards timely Alzheimer diagnosis: A self-powered amperometric biosensor for the neurotransmitter acetylcholine. Biosens Bioelectron 15, 607-614.

[50] Galvin JE, Tolea MI, Moore C, Chrisphonte S (2020) The Number Symbol Coding Task: A brief measure of executive function to detect dementia and cognitive impairment. PLoS One 15, e0242233.

[51] Braak H, Braak E (1997) Frequency of stages of Alzheimerrelated lesions in different age categories. Neurobiol Aging 18, 351-357.

[52] Ballard C, Gauthier S, Corbett A, Brayne C, Aarsland D, Jones E (2011) Alzheimer's disease. Lancet 377, 10191031.

[53] Livingston G, Sommerlad A, Orgeta V, Costafreda SG, Huntley J, Ames D, Ballard C, Banerjee S, Burns A, CohenMansfield J, Cooper C, Fox N, Gitlin LN, Howard R, Kales HC, Larson EB, Ritchie K, Rockwood K, Sampson EL, Samus Q, Schneider LS, Selbæk G, Teri L, Mukadam N (2017) Dementia prevention, intervention, and care. Lancet 390, 2673-2734.

[54] Falco AD, Cukierman DS, Hauser-Davis RA, Rey NA (2016) Doença de Alzheimer: Hipóteses etiológicas e perspectivas de tratamento. Quím Nova 39, 63-80.

[55] Musiek ES, Holtzman DM (2012) Origins of Alzheimer's disease: Reconciling cerebrospinal fluid biomarker and neuropathology data regarding the temporal sequence of amyloid-beta and tau involvement. Curr Opin Neurol 25, 715-720.

[56] Hardy J, Allsop D (1991) Amyloid deposition as the central event in the aetiology of Alzheimer's disease. Trends Pharmacol Sci 12, 383-388.

[57] Lemere CA (2012) Immunotherapy for Alzheimer's disease: Hoops and hurdles. Mol Neurodegener 8, 36.

[58] Rostagno A, Holton JL, Lashley T, Revesz T, Ghiso J (2010) Cerebral amyloidosis: Amyloid subunits, mutants, and phenotypes. Cell Mol Life Sci 67, 581-600. 
[59] Sherrington R, Rogaev EI, Liang Y, Rogaeva EA, Levesque G, Ikeda M, Chi H, Lin C, Li G, Holman K, Tsuda T, Mar L, Foncin JF, Bruni AC, Montesi MP, Sorbi S, Rainero I, Pinessi L, Nee L, Chumakov I, Pollen D, Brookes A, Sanseau P, Polinsky RJ, Wasco W, Da Silva HA, Haines JL, Perkicak-Vance MA, Tanzi RE, Roses AD, Fraser PE, Rommens JM, St George-Hyslop PH (1995) Cloning of a gene bearing missense mutations in early-onset familial Alzheimer's disease. Nature 375, 754-760.

[60] Verlinde VJA, Van der Geest JOSN, de Brujin RFAG, Hofman A, Koudstall PJ, Arfan Ilkram M (2016) Trajectories of decline in cognition and daily functioning in preclinical dementia. Alzheimers Dement 12, 144-153.

[61] Sørensen L, Nielsen M (2018) Ensemble support vector machine classification of dementia using structural MRI and mini-mental state examination. J Neurosci Methods 302, 44-74.

[62] Fiskea A, Holmboeb K (2019) Neural substrates of early executive function development. Dev Rev 52, 42-62.

[63] Emberson LL, Zinszer BD, Raizada RDS, Aslin RN (2017) Decoding the infant mind: Multivariate pattern analysis (MVPA) using fNIRS. PLoS One 12, e0172500.

[64] McKenna R, Rushe T, Woodcock KA (2017) Informing the structure of executive function in children: A meta-analysis of functional neuroimaging data. Front Hum Neurosci 11, 154.

[65] Posner MI, Rothbart MK (2007) Research on attention networks as a model for the integration of psychological science. Ann Rev Psychol 58, 1-23.

[66] Gao W, Zhu H, Giovanello KS, Smith JK, Shen D, Gilmore JH, Lin W (2009) Evidence on the emergence of the brain's default network from 2-week-old to 2-year-old healthy pediatric subjects. Proc Natl Acad Sci U S A 106, 6790-6795.

[67] Ducan J, Mowen A (2000) Common regions of the human frontal lobe. Trends Neurosci 23, 475-483.

[68] Amso D, Scerif G (2015) The attentive brain: Insights from developmental cognitive neuroscience. Nat Rev Neurosci 16, 606-619.

[69] Graff-Radford J, Yong KXX, Apostolova LG, Bouwman FH, Carrillo M, Dickerson BC, Rabinovici GD, Schott JM, Jones DT, Murray ME (2021) New insights into atypical Alzheimer's disease in the era of biomarkers. Lancet Neurol 20, 222-234
[70] Palmqvist S, Schöll M, Strandberg O, Mattsson N, Stomrud E, Zetterberg H, Blennow K, Landau S, Jagust W, Hansson O (2017) Earliest accumulation of $\beta$-amyloid occurs within the default-mode network and concurrently affects brain connectivity. Nat Commun 8, 1214.

[71] Palmqvist S, Insel PS, Zetterberg H, Blennow K, Brix B, Stomrud E; Alzheimer's Disease Neuroimaging Initiative; Swedish BioFINDER study, Mattsson N, Hansson O (2019) Accurate risk estimation of $\beta$-amyloid positivity to identify prodromal Alzheimer's disease: Cross-validation study of practical algorithms. Alzheimers Dement 15, 194-204.

[72] Zhang Y, Wang S, Xia k, Jiang Y, Qian P (2021) Alzheimer's disease multiclass diagnosis via multimodal neuroimaging embedding feature selection and fusion. Inform Fusion $\mathbf{6}$, 170-183.

[73] Wang L, Gao T, Cai T, Li K, Zheng P, Liu J (2020) Cerebrospinal fluid levels of YKL-40 in prodromal Alzheimer's disease. Neurosci Lett 715, 134658.

[74] Scahill RI, Schott JM, Stevens JM, Rossor MN, Fox NC (2002) Mapping the evolution of regional atrophy in Alzheimer's disease. Proc Natl Acad Sci U S A 99, 47034707.

[75] Mendes KDS, Silveira RCCP, Galvão CM (2008) Integrative literature review: A research method to incorporate evidence in health care and nursing. Texto Contexto Enfermagem 17, 758-764.

[76] Santos CMC, Pimenta CAM, Nobre MRC (2007) A Estratégia Pico para a construção da pergunta de pesquisa e busca de evidências. Rev Latino-Am Enfermagem 15, 508511.

[77] Muraven M, Baumeister RF (2000) Self-regulation and depletion of limited resources: Does self-control resemble a muscle? Psychol Bull 126, 247-259.

[78] Kanai R, Rees G (2011) The structural basis of interindividual differences in human behaviour and cognition. Nat Rev Neurosci 12, 231-242.

[79] Moher D, Liberati A, Tetzlaff J, Altman DG; PRISMA Group (2009) Preferred reporting items for systematic reviews and meta-analyses: The PRISMA statement. PLoS Med 6, e1000097. 